\title{
COLGAJO RETROAURICULAR PARA RECONSTRUCCIÓN DE DEFECTOS DE LA CONCHA AURICULAR. DESCRIPCIÓN DE UN CASO
}

\section{Reconstruction of auricular conchal defects with postauricular island flap. A case report}

\author{
Patricia CORRIOLS-NOVAL; Francisco José HERRERO-FERNÁNDEZ; Guillermo Hernán de PIERO-BELMONTE \\ Hospital Universitario Marqués de Valdecilla. Servicio de Otorrinolaringología. Santander. España. \\ Correspondencia: patri16.92@gmail.com
}

Fecha de recepción: 12 de agosto de 2018

Fecha de aceptación: 24 de agosto de 2018

Fecha de publicación: 26 de agosto de 2018

Fecha de publicación del fascículo: 1 de diciembre de 2019

Conflicto de intereses: Los autores declaran no tener conflictos de intereses

Imágenes: Los autores declaran haber obtenido las imágenes con el permiso de los pacientes

Política de derechos y autoarchivo: se permite el autoarchivo de la versión post-print (SHERPA/RoMEO)

Licencia CC BY-NC-ND. Licencia Creative Commons Atribución-NoComercial-SinDerivar 4.0 Internacional

Universidad de Salamanca. Su comercialización está sujeta al permiso del editor

RESUMEN: Introducción y objetivo: Los defectos totales o subtotales de la región de la concha auricular suponen un reto para la reconstrucción quirúrgica. El colgajo retroauricular tiene como principal indicación la reparación de los defectos auriculares anteriores, especialmente los de concha auricular. Se lleva a cabo en un solo procedimiento, con la reconstrucción inmediata del defecto y cierre directo de la región donante. El objetivo de este caso es ilustrar la reconstrucción de un defecto de la concha auricular mediante un colgajo seguro y eficaz, desde el punto de vista oncológico y estético, como es el colgajo retroauricular. Descripción: Se presenta el caso de un varón de 78 años con carcinoma escamoso en la región de la concha auricular y cuyo defecto fue reconstruido mediante el colgajo retroauricular. En el postoperatorio precoz la evolución del colgajo fue favorable, presentando buena coloración y cicatrización óptima, al igual que la herida retroauricular del área donante. Discusión y Conclusiones: El colgajo retroauricular basado en la arteria auricular posterior constituye una aceptable alternativa en la reconstrucción de los defectos de la concha auricular que no son tributarios de cierre directo ni injerto local, manteniendo la anatomía del pabellón, y consiguiendo unos resultados estéticos óptimos en la región receptora de la concha, además de preservar la integridad del surco retroauricular.

Palabras clave: colgajo retroauricular; reconstrucción; concha auricular, defecto. 


\section{COLGAJO RETROAURICULAR PARA RECONSTRUCCIÓN DE DEFECTOS DE LA CONCHA AURICULAR. DESCRIPCIÓN DE UN CASO \\ CORRIOLS-NOVAL P ET AL}

SUMMARY: Introduction and objective: Total or partial concha defects are a challenge for surgical reconstruction. Postauricular flap is the best option to repair anterior auricular defects, above all those involving auricular concha. It is performed in just one surgical procedure, with immediately reconstruction of the defect and direct closing of the postauricular donor region. The main aim of these report case is to illustrate the concha auricular reconstruction after tumor exempt by means of an accurate and effective flap, from the oncological and esthetic point of view, as it is the postauricular flap. Description: A 78 years old men with squamous carcinoma located in concha region who underwent on reconstruction with postauricular flap after tumor removed. The postoperative follow up was successful, with optimum color and evolution of the flap and the postauricular wound. Discussion: Postauricular flap, based on posterior auricular artery, is an acceptable alternative for reconstruction of auricular concha defects that are not tributary of direct closing, preserving auricular pavilion anatomy and postauricular groove and also achieving excellent esthetic results.

Keywords: postauricular flap, reconstruction, auricular concha, defect.

\section{INTRODUCCIÓN}

Los defectos totales o subtotales de la región de la concha auricular suponen un reto para la reconstrucción quirúrgica $[1,2]$. El colgajo retroauricular tiene como principal indicación la reparación de los defectos auriculares anteriores, especialmente los de concha auricular. Se lleva a cabo en un solo procedimiento, con la reconstrucción inmediata del defecto y cierre directo de la región donante [3]. El objetivo del artículo es ilustrar la reconstrucción de un defecto de la concha auricular mediante un colgajo seguro y eficaz, desde el punto de vista oncológico y estético, como es el colgajo retroauricular.

\section{DESCRIPCION}

Varón de 78 años que presentaba en la región de la concha auricular izquierda, un tumor exofítico y redondeado de $1 \mathrm{~cm}$ de diámetro máximo, cuya anatomía patológica era compatible con carcinoma escamoso (Figura 1). Se realizó resección de la neoplasia, que invadía el pericondrio y cartílago subyacente, quedando un defecto residual amplio en la región de la concha, no tributario de injerto ni cierre directo, por lo que se decidió el cierre del defecto con el colgajo retroauricular. Para ello se dibujó en la piel de la región mastoidea las dimensiones del colgajo acorde al área del defecto (Figura 2), para posteriormente levantarlo y despegarlo en isla, rotándolo sobre su pedículo a modo de bisagra y traspasándolo a hacia la región anterior del pabellón auricular (Figura 3). Posteriormente se suturó para cubrir el defecto de la concha y la zona retroauricular se cerró mediante sutura directa. En el postoperatorio precoz la evolución del colgajo y de la herida retroauricular fue favorable, presentando buena coloración y cicatrización óptima (Figura 4).

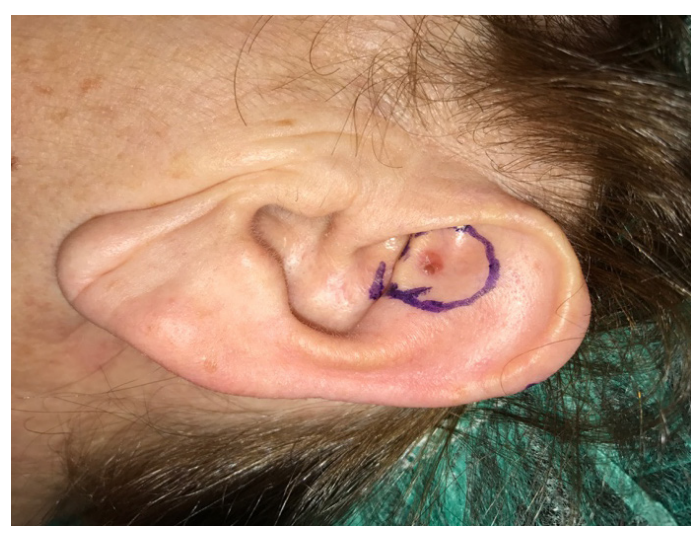

Figura 1. Tumor redondeado de $1 \mathrm{~cm}$ de diámetro máximo, localizado en la región de la concha auricular, compatible con carcinoma escamoso. Diseño de resección con $1 \mathrm{~cm}$ de margen alrededor de la tumoración. 


\section{COLGAJO RETROAURICULAR PARA RECONSTRUCCIÓN DE DEFECTOS DE LA CONCHA AURICULAR. DESCRIPCIÓN DE UN CASO \\ CORRIOLS-NOVAL P ET AL}

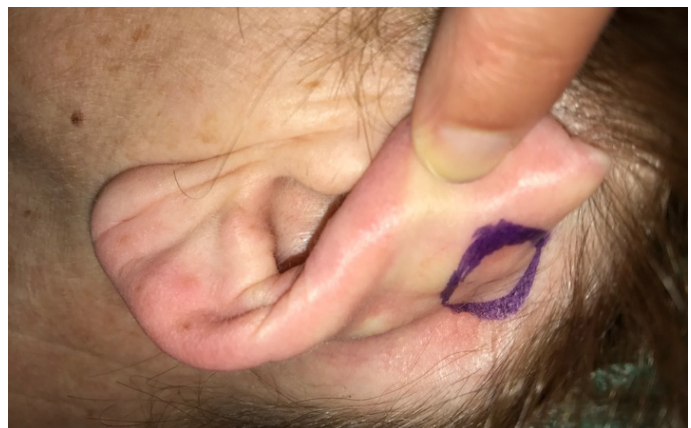

Figura 2. Diseño del colgajo retroauricular para la cobertura del defecto generado tras la resección del tumor.

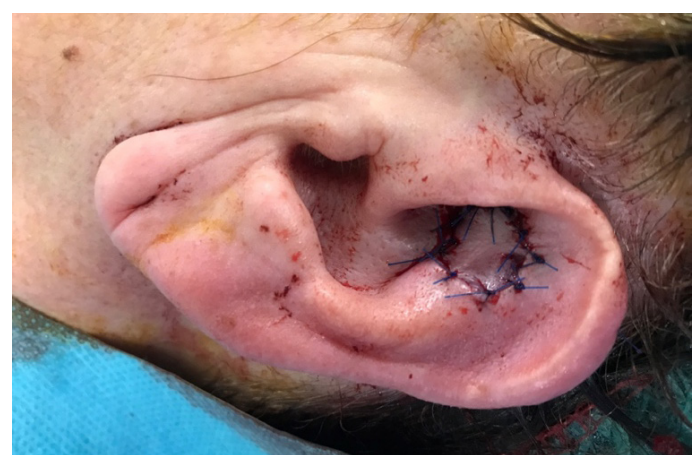

Figura 3. Trasposición y acoplamiento del colgajo retroauricular en la región anterior para cobertura del defecto de la concha provocado tras realizar exéresis del tumor.

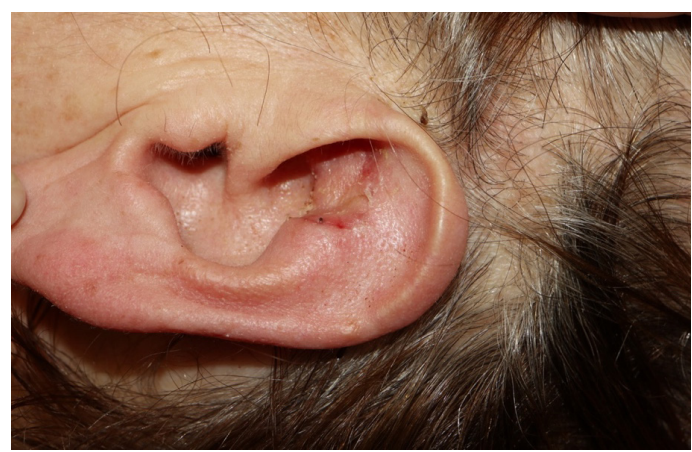

Figura 4: Seguimiento a los 15 días de la cirugía, dónde se observa la evolución satisfactoria del colgajo, con una coloración y acoplamiento óptimos, así como buena estética de la región de la concha auricular.

\section{DISCUSIÓN}

Los defectos totales o subtotales de la región de la concha auricular suponen un reto para la reconstrucción quirúrgica. El colgajo retroauricular tiene como principal indicación la reparación de los defectos auriculares anteriores, especialmente los de concha auricular [1].

La principal ventaja es que se lleva a cabo en un solo procedimiento, con reconstrucción inmediata del defecto y con un cierre directo de la región donante. Existen varias limitaciones para su uso, como la existencia de cirugía previa parotídea o del conducto auditivo externo, así como ligadura de la carótida externa ya que incrementan el riesgo de necrosis del colgajo por fallo en la vascularización. Por otro lado, localizaciones alejadas de la concha auricular, pueden limitar la capacidad de rotación del colgajo generando excesiva tensión para su emplazamiento en la parte anterior del pabellón, aumentando igualmente el riesgo de pérdida de este $[1,2]$.

Anatomía. La piel de la región mastoidea presenta una rica vascularización a través de las arterias auricular superior y la arteria auricular posterior, ésta última el pedículo vascular del colgajo [2]. Es una arteria anatómicamente constante, que nace de la arteria carotidea externa y a su llegada a la región auricular pasa entre el cartílago auricular y la apófisis mastoides. A ese nivel da varias ramas, siendo la de interés para el colgajo retroauricular la rama auricular, que irriga al músculo auricular posterior y se ramifica en pequeñas arterias que rodean superficialmente el pabellón auricular y terminan anastomosándose con otras ramas procedentes de la arteria temporal superficial que irriga la región más anterior del pabellón [2,3].

TÉcnica. Se debe marcar la forma y el tamaño del tumor para a continuación realizar el diseño del colgajo en la región auricular posterior, haciendo coincidir en altura y área el defecto de la región 


\section{COLGAJO RETROAURICULAR PARA RECONSTRUCCIÓN DE DEFECTOS DE LA CONCHA AURICULAR. DESCRIPCIÓN DE UN CASO \\ CORRIOLS-NOVAL P ET AL}

auricular anterior con el área dadora retroauricular [3]. Lo ideal es hacer que el centro del defecto anterior quede proyectado sobre el surco retroauricular, evitando así que el pedículo quede expuesto cuando hagamos el cierre de la región donante [2, 4].

Tras la resección de la tumoración anterior y la configuración del defecto a reconstruir, se procede a la elevación del colgajo, plegando la oreja hacia delante para aumentar el campo de trabajo. Dado que es un colgajo en isla, se seccionan los márgenes en su totalidad de forma vertical, con mayor profundidad en el límite posterior que a nivel del surco auricular, que es dónde se encuentra la AAP. Con la oreja plegada hacia delante se toma el borde anterior del colgajo y a continuación se coloca la oreja a su posición anatómica, traspasando el colgajo por el defecto auricular evitando tensión o torsión excesiva del mismo que pueda lesionar su pedículo $[4,5]$.

Se procede a fijar el colgajo con 4 suturas no reabsorbibles 4.0 en los puntos horarios $(3,9,12 \mathrm{y}$ 6) completándolo posteriormente con puntos intermedios. El cierre del defecto posterior se realiza de forma directa afrontando bordes, con una sutura lineal no reabsorbible con puntos sueltos sobre el surco auricular posterior.

\section{CONCLUSIONES}

El colgajo retroauricular basado en la arteria auricular posterior es una buena alternativa reconstructiva de los defectos de la concha auricular que comprometen al cartílago subyacente, y que no son tributarios de cierre directo ni injerto local, suponiendo una mejor alternativa estética que la cicatrización por segunda intención. Se consigue una resección segura desde el punto de vista oncológico, y una reconstrucción óptima de la anatomía del pabellón, con una buena textura y coloración cutánea de la región de la concha, manteniendo además la integridad del surco retroauricular.

\section{AGRADECIMIENTOS}

Agradecimiento al Servicio de Cirugía Plástica del Hospital universitario Marqués de Valdecilla, y en especial al Dr. Francisco José Herrero Fernández por la cesión de las imágenes para el reporte de este caso clínico.

\section{BIBLIOGRAFÍA}

1. Roche AM, Griffin M, Shelton R, Urken ML. The folded postauricular flap: A novel approach to reconstruction of large full thickness defects of the conchal bowl. Am J Otolaryngol. 2017;38:706-9.

2. Krespi YP, Ries WR, Shugar JM, Sisson GA. Auricular reconstruction with postauricular myocutaneous flap. Otolaryngol Head Neck Surg. 1983;91:193-6.

3. Talmi YP, Liokumovitch P, Wolf M, Horowitz Z, Kopolovitch J, Kronenberg J. Anatomy of the postauricular island "revolving door" flap ("flipflop" flap). Ann Plast Surg. 1997;39:603-7.

4. Ferrario D, Molinari LM, Galimberti GN, Galimberti RL. Island interpolation flap (revolving door) for the reconstruction of surgical defects of the ear auricle. Piel 2015; 30:52-9.

5. Dessy LA, Figus A, Fioramonti P, Mazzocchi M, Scuderi N. Reconstruction of anterior auricular conchal defect after malignancy excision: revolving-door flap versus full-thickness skin graft. J Plast Reconstr Aesthet Surg. 2010; 63:746-52. 